\title{
GIS-BASED SITE SELECTION FOR UNDERGROUND NATURAL RESOURCES USING FUZZY AHP-OWA
}

\author{
Sabzevari, A. R. ${ }^{a}$ and M. R. Delavar ${ }^{b}$ \\ ${ }^{a}$ GIS Dept., School of Surveying and Geospatial Eng., College of Eng., University of Tehran, Tehran, Iran- \\ a.sabzevari@ut.ac.ir \\ ${ }^{\mathrm{b}}$ Center of Excellence in Geomatics Eng. in Disaster Management, School of Surveying and Geospatial Eng., College of Eng., \\ University of Tehran, Tehran, Iran - \\ mdelavar@ut.ac.ir \\ commission IV, WG IV/3
}

KEY WORDS: Site Selection, Natural Resource, Multi-Criteria Decision Making, Ordered Weighted Average, Fuzzy AHP, Fuzzy AHP-OWA

\section{ABSTRACT:}

Fuel consumption has significantly increased due to the growth of the population. A solution to address this problem is the underground storage of natural gas. The first step to reach this goal is to select suitable places for the storage. In this study, site selection for the underground natural gas reservoirs has been performed using a multi-criteria decision-making in a GIS environment. The "Ordered Weighted Average" (OWA) operator is one of the multi-criteria decision-making methods for ranking the criteria and consideration of uncertainty in the interaction among the criteria. In this paper, Fuzzy AHP_OWA (FAHP_OWA) is used to determine optimal sites for the underground natural gas reservoirs. Fuzzy AHP_OWA considers the decision maker's risk taking and risk aversion during the decision-making process. Gas consumption rate, temperature, distance from main transportation network, distance from gas production centers, population density and distance from gas distribution networks are the criteria used in this research. Results show that the northeast and west of Iran and the areas around Tehran (Tehran and Alborz Provinces) have a higher attraction for constructing a natural gas reservoir. The performance of the used method was also evaluated. This evaluation was performed using the location of the existing natural gas reservoirs in the country and the site selection maps for each of the quantifiers. It is verified that the method used in this study is capable of modeling different decision-making strategies used by the decision maker with about 88 percent of agreement between the modeling and test data.

\section{INTRODUCTION}

In recent years, fuel consumption has increased significantly due to the growth of the population. A solution to address this problem is the underground storage of natural gas. The first step to reach this goal is to select suitable places for the storage. The storage should be carried out in a way that the excess of natural gas is stored in the underground storage during the hot and low consumption seasons, to use the stored gas during the high consumption periods. In this study, the site selection for the underground natural gas reservoirs has been carried out using multi-criteria decision making in a GIS environment.

Zangeneh et al., (2011) selected the optimum sites for underground reservoirs of natural gas using a GIS-based approach. They proposed the suitable sites for underground reservoirs of natural gas using Boolean logic and Index Overlay (IO) methods in a GIS-based framework and showed that IO concludes better results. Anagnostopoulos et al., (2008) surveyed the linguistic multi-criteria decision making using fuzzy set theory, the ideal solution and the anti-ideal solution in the site selection problem. They found the ambiguity of data using the linguistic variables, then involved human decision making by the development of decision-making rules and their modeling of using fuzzy functions. Their proposed method considered the ideal solution and the anti-ideal solution and assessed each alternative regarding distance as well as similarity to the ideal solution and the anti-ideal solution. The distance and similarity measured for fuzzy numbers were used, and the decision rules guided their aggregation to construct decision functions. Further, Ordered weighted Averaging (OWA) operators with maximal entropy were used to aggregate across all criteria and determine the overall score of each alternative, designed a new spatial multi-criteria decision analysis (SMCDA) software tool for selecting suitable sites for Managed Aquifer Recharge (MAR) systems. Their new SMCDA software tool functions based on the combination of existing multicriteria evaluation methods with modern decision analysis techniques including non-compensatory screening, criteria standardization and weighting where AHP has been combined with WLC and OWA. Eldrandaly \& AL-Amari, (2014) presented a novel decision-making framework in which Expert Systems (ES), and GIS-based multi-criteria evaluation techniques (Analytical Network Process (ANP) and fuzzy quantifiers-guided OWA operators (GIS-based ANP-OWA)) were integrated systematically to facilitate the selection of suitable sites for building new tourism facilities. First, ES was used for recommending the proper site selection criteria and their interdependence relationships. Then, the GIS-based ANPOWA was used to perform the spatial data analysis necessary to generate a wide range of possible candidate sites scenarios taking into accounts both the interdependence relationships between sitting criteria and the level of risk the decision-makers wish to assume in their multi-criteria evaluation. Gorsevski et al., (2012) presented a GIS-based multi-criteria decision analysis approach for evaluating the suitability for landfill site selection in the Polog Region, Macedonia. Their multi-criteria decision framework considered environmental and economic factors which were standardized by fuzzy membership functions and combined with integration of AHP and OWA techniques. The AHP was used for the elicitation of generate a wide range of decision alternatives for addressing uncertainty associated with the interaction between and among multiple criteria. The usefulness of the approach was illustrated 
by different OWA scenarios that report landfill suitability on a scale between 0 and 1 . The OWA scenarios were intended to quantify the level of risk taking (i.e., optimistic, pessimistic, and neutral) and to facilitate a better understanding of patterns that emerge from the decision alternatives involved in the decisionmaking process. Soltanalizadeh et al., (2014) selected the best site for a natural cave suitable for petroleum storage using a combination of Fuzzy AHP and TOPSIS ${ }^{1}$. Zhou \& Wu, (2012) selected a site for building a new hospital in Haidian District of Beijing using GIS-based Multi-Criteria Analysis (MCA). Using AHP and Rank Order Method (ROM) for the weight setting on factor criteria, necessity tests, and sensitivity tests were applied to check which criteria are necessary and how the results are sensitive to their weight change. They concluded that GIS-based MCA with necessity and sensitivity tests proposes a novel and useful reference to other site selection decision makers, and also provides constructive tools for the public administration to set up efficient databases for decision makers to carry out spatial analyses. Grataloup et al., (2009) determined the optimum site for $\mathrm{CO} 2$ underground storage in deep saline aquifers in Paris. They considered two criteria classified into "killer criteria" and "site-qualification criteria", whose combinations allowed identifying potential sites and the most appropriate ones. Malczewski, (2006) analyzed the land-use suitability using GISbased multi-criteria evaluation and used OWA method with fuzzy quantifiers in his study. He showed that how different decision-makings (derived from different quantifiers including "all", "almost all", "most", "half", "a few", "at least a few" and "at least one") can produce different results and compared the maps of these results together. Farazmanesh et al., (2010) located the public parking in Isfahan using GIS, multi-criteria decision-making, and fuzzy logic. Rajabi et al., (2011) compared some multi-criteria decision-making methods including AHP, AHP-OWA and Fuzzy AHP-OWA for residential complex site selection in Tabriz and concluded that Fuzzy AHP-OWA is the best method for residential complex site selection; because it considers risk-taking of decision makers and uses Fuzzy conceptual quantifiers.

\section{FUZZY ANALYTIC HIERARCHY PROCESS (FAHP)}

Fuzzy Analytic Hierarchy Process ${ }^{2}$ embeds the fuzzy theory to Analytic Hierarchy Process ${ }^{3}$, which was advanced by Saaty Saaty, (1980). AHP is a broadly used decision-making method in numerous multi-criteria decision-making issues. It takes the pair-wise comparisons of various alternatives with relevant to different criteria and produces a decision support method for multicriteria decision issues. In a general AHP model, the goal is on the first level, the criteria are on the second level and subcriteria are on the third level. Finally, the alternatives are on the fourth level Kilincci \& Onal, (2011).

Since basic AHP does not comprise ambiguity for personal decisions, it has been developed by profiting from the fuzzy logic approach. In FAHP, the pairwise comparisons of criteria and the alternatives are carried out through the linguistic variables, which are described by triangular numbers Kilincci \& Onal, (2011). One of the earliest fuzzy AHP application was conducted by Van Laarhoven \& Pedrycz, (1983). They represented the triangular membership functions for the pairwise comparisons. Later, Buckley, (1985) has contributed to the issue by defining the fuzzy priorities of comparison

\footnotetext{
${ }^{1}$ Technique for Order Preference by Similarity to Ideal Solution ${ }^{2}$ FAHP

${ }^{3}$ AHP
}

proportions having triangular membership functions. Chang, (1996) also presented a new approach associated to the usage of triangular numbers in pair-wise comparisons. Eventhough, there are some more techniques embedded in FAHP, within the scope of this study, Buckley's methods (Buckley, (1985)) is applied to define the relative prominence weights for both the criteria and the alternatives.

\section{OREDERED WEIGHTED AVERAGING (OWA)}

In all decision making problems several criteria should be considered Zarghami et al., (2008). The GIS-based multicriteria evaluation procedures involve a set of spatially defined alternatives (e.g. parcels of land) and a set of evaluation criteria represented as map layers Malczewski, (2006).

OWA method is one of the multi-criteria decision making methods Yager, (1988). Yager (1988) Yager, (1988) introduced OWA operators. OWA is a method for ordering criteria and considering uncertainty in the critera interaction Gorsevski et al., (2012).

Given the input data ( criterion map layers and criterion weights), the OWA operator is defined as OWA: $R \rightarrow R$ function. With a set of order weights $w=w_{1}, w_{2}, \ldots, w_{n}$ such that $w_{j} \in[0,1]$ and $\sum_{j=1}^{\infty} w_{j}=1, j=1,2, \ldots, n$ and also with having input data $X=x_{1}, x_{2}, \ldots, x_{n}$, OWA operator is defined as Eq. 1 Yager, (1988):

$O W A=\sum_{j} w_{j} z_{i, j}$

Where $z_{i 1} \geq z_{i 2} \geq \ldots \geq z_{\text {in }}$ is the descending arranges set of $X$ Malczewski et al., (2003; Yager, (1988).

\section{QUANTIFIER-GUIDED OWA OPERATORS}

Quantifier-guided OWA achieved by integrating fuzzy linguistic quantifiers with OWA operators. Different quantifiers could be divided into two major groups: (a) absolute quantifiers for linguistic variables like "about 7" and "almost 4", and (b) relative quantifiers like "some" and "half". In this research, a class of relative quantifiers, named "Regular Increasing Monotone (RIM)" is used. For describing this class of quantifiers, Eq. 2 could be applied (Fullér, (1996)):

$Q(p)=p^{\alpha}, 0 \leq p \leq 1 \quad$ and $\quad \alpha \geq 0$

By varying $\alpha$, different decision approaches and their operators could be obtained. Different decision approaches and their matching $\alpha$ have been showed in Table 1. Malczewski, (2006):

Table 1. Different decision strategies and their matching $\alpha$.

\begin{tabular}{|c|c|}
\hline decision strategy & $\boldsymbol{\alpha}$ \\
\hline at least one & 0.0001 \\
\hline few & 0.5 \\
\hline half & 1 \\
\hline most & 2 \\
\hline all & 1000 \\
\hline
\end{tabular}

The order weights vector $v$ can be obtained from RIM quantifiers. Visit Eq.3 Malczewski, (2006): 
$v_{j}=\left(\frac{\sum_{k=1}^{j} w_{k}}{\sum_{k=1}^{n} w_{k}}\right)^{\alpha}-\left(\frac{\sum_{k=1}^{j-1} w_{k}}{\sum_{k=1}^{n} w_{k}}\right)^{\alpha}$

Where $w$ is the relative criteria weights vector. Since the relative weights applied in this reaearch is obtained by AHP weighting approach, $w$ will be a normal vector and as a result $\sum_{k=1}^{n} w_{k}=1$. Therefore, Eq. 3 abridged to Eq.4:

$v_{j}=\left(\sum_{k=1}^{j} w_{k}\right)^{\alpha}-\left(\sum_{k=1}^{j-1} w_{k}\right)^{\alpha}$

\section{METHODOLOGY}

In this method, the OWA method is used to collect information. The Q-OWA method (Section 4) is used for computing the ordered weights. As mentioned in Section 3, the computation of ordered weight is done using Eq. 4 in which $\alpha$ is the decision parameter, and by its variation, different decision strategies could be taken (Table 1).

As mentioned is section 3 , the values of the w vector, are the criterion weights. Consequently, to use the Q-OWA method, the criterion weights should be present. In this part of the research, the weight of the criteria has been determined using the Fuzzy AHP method.

To determine the weight of the criteria according to the Fuzzy AHP method, the opinions of ten experts in the natural gas reservoir area were used. A comparison among the criteria was carried out and according to the fuzzy AHP method, for each expert, a weight vector was obtained. Next, the final weight vector was averaged according to the ten expert opinions. This weight vector was used as the weight vector of the criteria using the Q-OWA method.

At this stage, using Table 1, various decision strategies can be considered using different values for $\alpha$. In this research, five decision-making strategies (five quantifiers) have been employed. With each decision-making strategy, an index map is obtained. In Section 5, the evaluation of this method has been investigated.

Figure 1 illustrates research methodology.

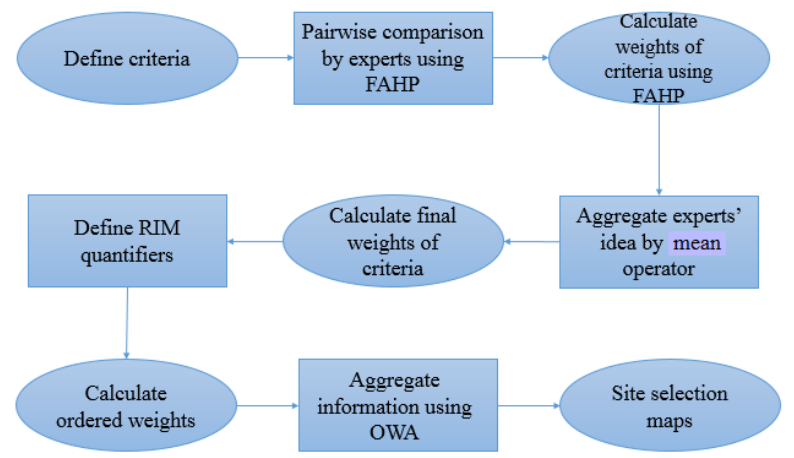

Figure1- Steps of site selection using Q-OWA Fuzzy AHP

\section{IMPLEMENTATION}

Various criteria are involved in the process of locating optimum gas storage locations. Gas consumption rate, temperature, distance from main transportation network, distance from gas production centers, population density and distance from gas distribution networks are the criteria used in this research.

Experts were asked to define the criteria weights. Opinions of ten experts are combined by the fuzzy analytical hierarchy process and the weight for each criterion is determined. OWA method is used to aggregate the weights, and for each expert, a weighing vector is computed. Table 2 shows the final criteria weights.

Table 2- Criteria weights computed by Fuzzy-AHP method

\begin{tabular}{|c|c|}
\hline Criterion & Weight \\
\hline Gas consumption & 0.28 \\
\hline Population density & 0.23 \\
\hline $\begin{array}{c}\text { Distance from gas production } \\
\text { centers }\end{array}$ & 0.09 \\
\hline Temperature & 0.1 \\
\hline $\begin{array}{c}\text { Distance from the main road } \\
\text { network }\end{array}$ & 0.08 \\
\hline Distance from gas pipeline & 0.22 \\
\hline
\end{tabular}

By computing the weights using Fuzzy-AHP method, the ordered weights are computed by Q-OWA method. In fact, the fuzzy-AHP weights are inputs of the Q-OWA. At this stage, a decision strategy should be adopted.

For the weight vector $\mathrm{w}$ and with the decision strategy "Most" $(\alpha=2)$, we have:

$$
v=\{0.078,0.182,0.1,0.13,0.118,0.392\}
$$

The vector $\mathrm{v}$ contains the ordered weights. These weights should be normalized and ordered descendingly. After normalizing the values of each criterion map cells, the cell values ranged between zero and one. In the next step, the cost and benefit criteria should be determined. Gas consumption and population are profit criteria in this research. Cell values for the six criteria were ordered by the Eq. 1 as the vector $u$.

In the final step, the criteria weights were aggregated by OWA operator. The aggregation process is done by Cartesian product of ordered criteria values (u vector) and ordered weights $(w)$ :

$O W A_{i}=v \cdot u$

Where the OWA $\mathrm{A}_{\mathrm{i}}$ is the final weight of the cell, $v$ is weight vector constructed from combination of the weights computed by Fuzzy-AHP and OWA fuzzy conceptual quantifiers. " $u$ " is the values of the criteria for a cell ordered in a descending manner.

The decision strategies used in Q-OWA method are shown in Table 1.

For each decision strategy in Table 2, a map showing the optimum locations of the natural gas reservoir was produced. These maps are shown in Figures 2 to 6 . 


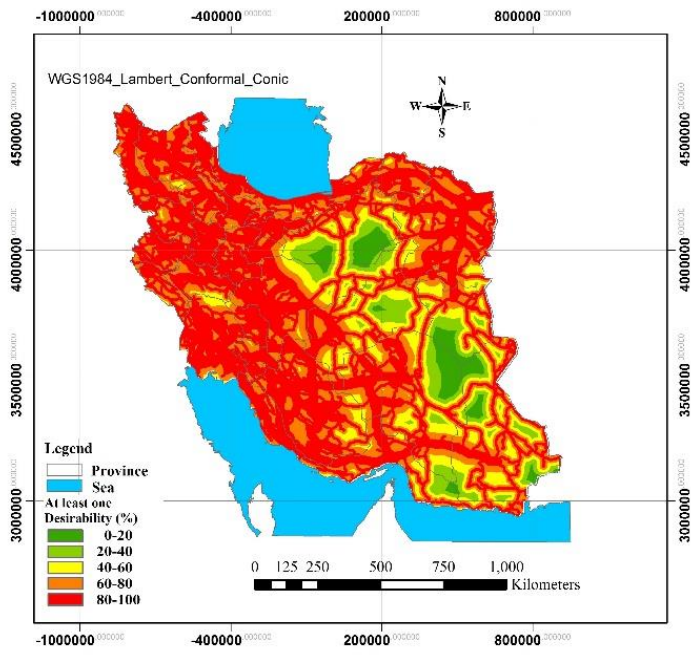

Figure 2 Site selection map of "at least one" quantifier

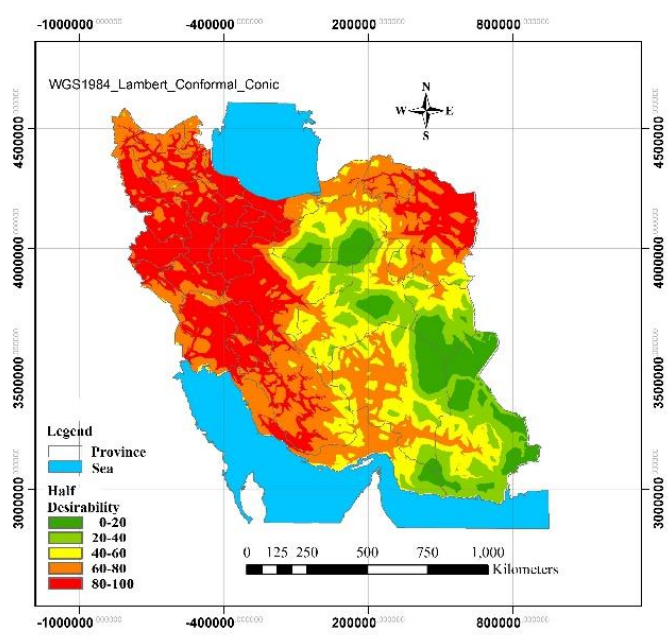

Figure 4 Site selection map of "half" quantifier

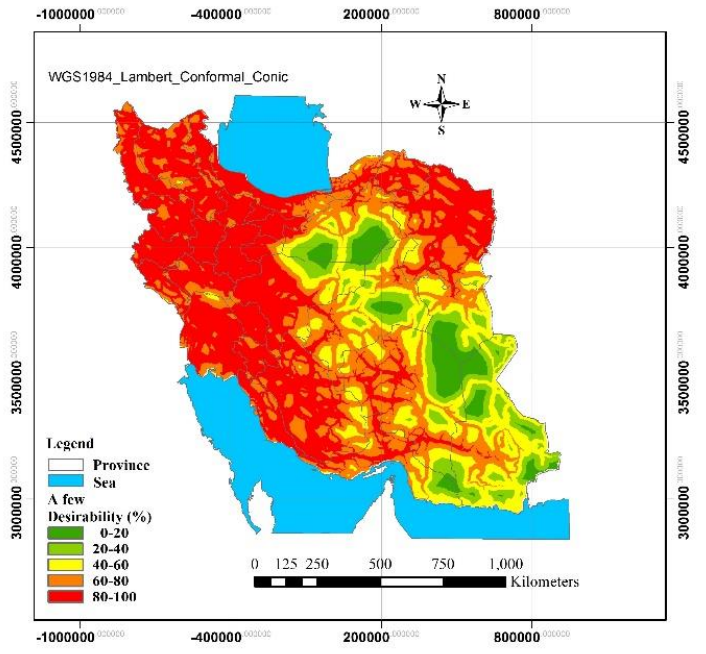

Figure3- Site selection map of "a few" quantifier

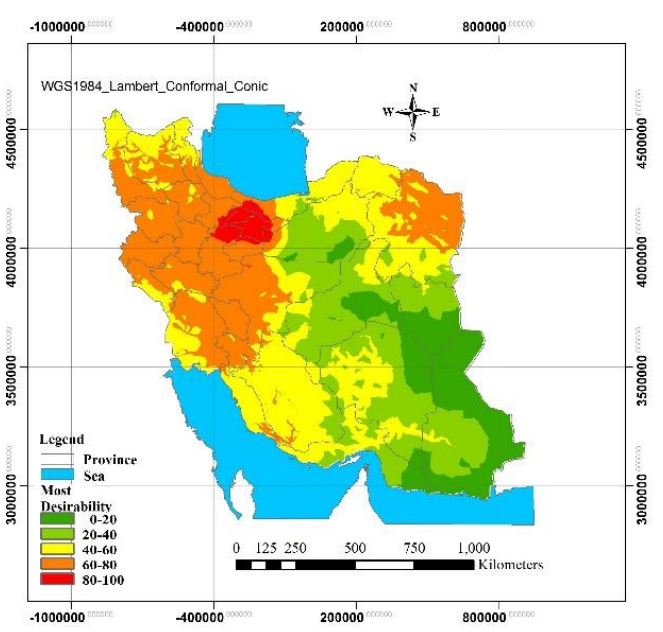

Figure5- Site selection map of "most quantifier"

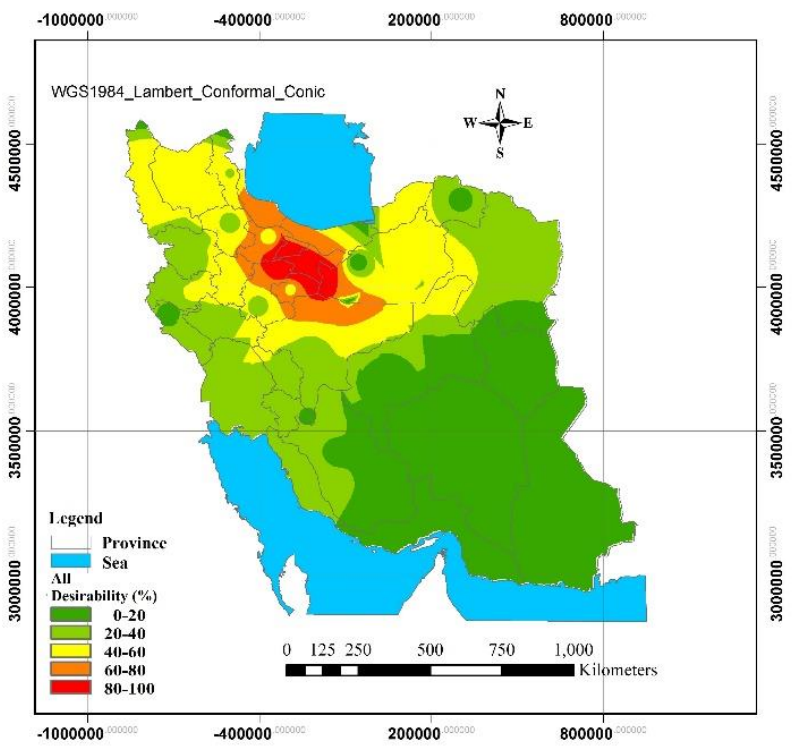

Figure 6- Site selection map of "all" quantifier 


\section{EVALUATION}

The evaluation of three procedures in this research was assessed by expert's ideas based on the location of ten existing reservoirs in the country. 30 experts participate in this evaluation. Figure 7 illustrates the location of the ten existing reservoirs in the country.

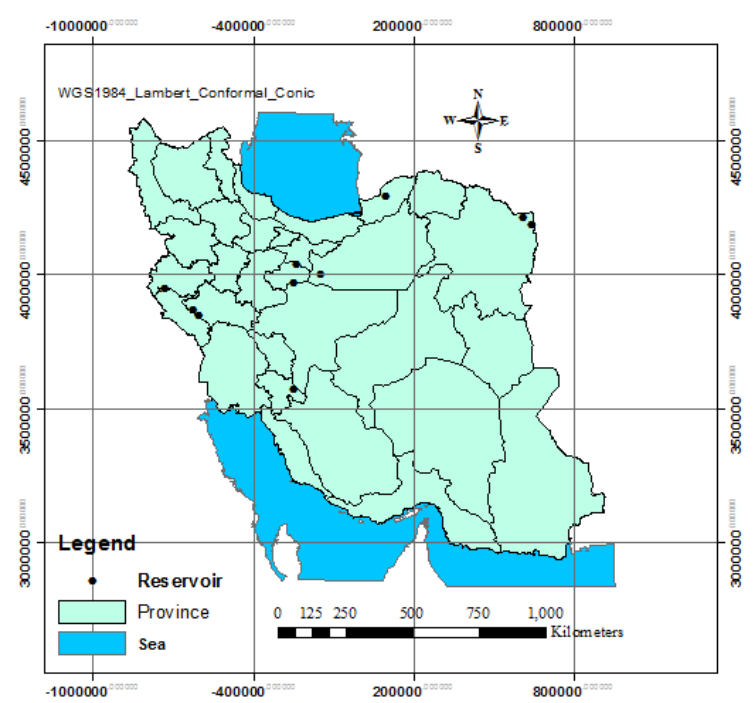

Figure 7- Location of 10 existing reservoirs in the country

In this research, utility of results for each decision strategy were divided to 5 classes: (1)- $0 \%$ to $20 \%$ (very bad), (2)- $20 \%$ to $40 \%$ (bad), (3)- $40 \%$ to $60 \%$ (average), (4)- 60\%-80\% (good) and (5)- $80 \%$ to $100 \%$ (very good).

Each expert selects a quantifier to evaluate the results. Then, based on the criteria maps and values for the ten existing reservoirs, three optimum located reservoirs will be selected by each expert. If the selected reservoirs, are located in the "good" region or "very good" region in the site selection map, it can be concluded that employed method with the selected quantifier has good performance for the site selection of underground gas reservoirs.

Five of the thirty experts selected "half" quantifier, eleven experts selected "most" quantifier and fifteen experts selected "all" quantifier. Thirteen reservoirs of all fifteen reservoirs selected by experts who selected "half" strategy were in "good" or "very good" class. The results of other strategies are shown in Table 3.
Table 3- Reservoirs which are in "good" or "very good" class

\begin{tabular}{|c|c|c|}
\hline Decision strategy & Selected reservoirs & All reservoirs \\
\hline Half & 13 & 15 \\
\hline Most & 28 & 33 \\
\hline All & 37 & 42 \\
\hline
\end{tabular}

Results show that the proposed method could model the decision maker's subjective preferences with $88 \%$ of efficiency for decision makers who choose "all" strategy.

Figure 8 shows the efficiency of the method used in this paper for decision makers who chose "half", "most" and "all" quantifiers.

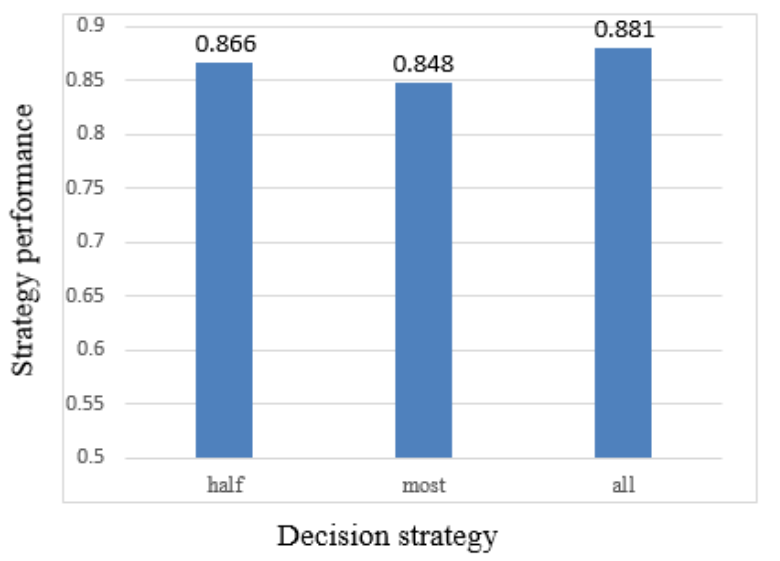

Figure 8- Percent of performance of "Q-OWA and Fuzzy AHP"

\section{CONCLUSION}

In this study, site selection for the underground natural gas reservoirs has been carried out using multi-criteria decisionmaking in a GIS environment.

Gas consumption rate, temperature, distance from main transportation network, distance from gas production centers, population density and distance from gas distribution networks are the criteria used in this research.

Output maps for "at least one" and "all" quantifiers are the same for the three methods.

According to output maps, northeast, west, northwest and north of Iran have higher priority for finding underground gas reservoirs.

For different quantifiers (different decision strategies) expect different results from the problem.

The proposed method in this paper was evaluated by 30 expert's opinions and it was concluded that the proposed method can model the decision maker's subjective preferences with $88 \%$ of efficiency for decision makers who choose "all" strategy. The efficiency for those who chose "half" and "most" strategy is $86 \%$ and $84 \%$ respectively. 


\section{REFERENCES}

Anagnostopoulos, K., Doukas, H., \& Psarras, J. (2008). A linguistic multicriteria analysis system combining fuzzy sets theory, ideal and anti-ideal points for location site selection. Expert Systems with Applications, 35(4), 2041-2048.

Buckley, J. J. (1985). Fuzzy hierarchical analysis. Fuzzy sets and systems, 17(3), 233-247.

Chang, D.-Y. (1996). Applications of the extent analysis method on fuzzy AHP. European Journal of Operational Research, 95(3), 649-655.

Eldrandaly, K. A., \& AL-Amari, M. A. (2014). An expert GIS-based ANP-OWA decision making framework for tourism development site selection. International Journal of Intelligent Systems and Applications, 6(7), 1.

Fullér, R. (1996). OWA operators in decision making. Exploring the limits of support systems, TUCS General Publications, 3, 85-104.

Gorsevski, P. V., Donevska, K. R., Mitrovski, C. D., \& Frizado, J. P. (2012). Integrating multi-criteria evaluation techniques with geographic information systems for landfill site selection: a case study using ordered weighted average. Waste management, 32(2), 287-296.

Grataloup, S., Bonijoly, D., Brosse, E., Dreux, R., Garcia, D., Hasanov, V., . . . Thoraval, A. (2009). A site selection methodology for $\mathrm{CO}_{2}$ underground storage in deep saline aquifers: case of the Paris Basin. Energy Procedia, 1(1), 2929-2936.

Kilincci, O., \& Onal, S. A. (2011). Fuzzy AHP approach for supplier selection in a washing machine company. Expert Systems with Applications, 38(8), 9656-9664.

Malczewski, J., 2006. Ordered weighted averaging with fuzzy quantifiers: GIS-based multicriteria evaluation for land-use suitability analysis. International Journal of Applied Earth Observation and Geoinformation, 8(4), 270-277.
Malczewski, J., Chapman, T., Flegel, C., Walters, D., Shrubsole, D., \& Healy, M. A. (2003). GISmulticriteria evaluation with ordered weighted averaging (OWA): case study of developing watershed management strategies. Environment and Planning A, 35(10), 1769-1784.

Rajabi, M., Mansourian, A., \& Taleai, M. (2011). A comparison study between AHP, AHP-OWA and Fuzzy AHP-OWA multi-criteria decision-making methods for site selection of residential complexes in Tabriz-Iran. Journal of Environmental Studies, 37(57), 77-92.

Saaty, T. L. (1980). The analytic hierarchy process: planning, priority setting, resources allocation. New York: McGraw.

Soltanalizadeh, A., Ramezanzadeh, A., \& Jalali, M. (2014). Determining appropriate natural caves for underground crude oil storage by admixture FAHP and TOPSIS methods. Journal of Engineering Geology, 8(3), 2239-2260.

Van Laarhoven, P., \& Pedrycz, W. (1983). A fuzzy extension of Saaty's priority theory. Fuzzy sets and systems, 11(1-3), 229-241.

Yager, R. R. (1988). On ordered weighted averaging aggregation operators in multicriteria decisionmaking. Systems, Man and Cybernetics, IEEE Transactions on, 18(1), 183-190.

Zangeneh, M., Delavar, M., Moshiri, B., Ghavampour, S., \& Effati, M. (2011). Site selection of underground storage of natural gas reservoirs using GIS. Journal of Geomatics Science and Technology, I(1), 14

Zarghami, M., Szidarovszky, F., \& Ardakanian, R. (2008). A fuzzy-stochastic OWA model for robust multi-criteria decision making. Fuzzy Optimization and Decision Making, 7(1), 1-15.

Zhou, L., \& Wu, J. (2012). GIS-based multi-criteria analysis for hospital site selection in Haidian district of Beijing. Department of Industrial Development, IT and Land Management. Hogskolan I Gavle, 1-50. 